\title{
28 Research Square \\ Sudden death of adults in Togo: Autopsy results of a series of 318 cases
}

\section{Tchin Darre ( $\sim$ paolodarre@yahoo.fr)}

Universite de Lome Faculte des Sciences de la Sante

\section{Toukilnan Djiwa}

University of Lomé

Gado Napo-Koura

University of Lomé

\section{Research note}

Keywords: Sudden death, autopsy, myocardial infarction, pulmonary embolism, Togo

Posted Date: December 3rd, 2019

DOI: https://doi.org/10.21203/rs.2.18141/v1

License: (c) (1) This work is licensed under a Creative Commons Attribution 4.0 International License.

Read Full License 


\section{Abstract}

Objectives: The purpose of the study was to determine the circumstances of occurrence of these sudden deaths, risk factors, to identify the causes of sudden death in adults at autopsy.

Results: A total of 318 sudden death cases were recorded. The sex ratio $(M / F)$ was 1.8 , and the mean age was $43 \pm 0.36$ years. Sudden deaths were the second most common reason for autopsies after traffic accidents. The place of death was home in $76.7 \%$ of cases and in hospitals in $23.3 \%$. Obesity was noted in $59.4 \%$, with an umbilical adipose panicle varying between 7 and $12 \mathrm{~cm}$ thick. Cardiovascular causes excluding cerebral involvement ( $n=173$ cases, $54.40 \%$ ) followed by pulmonary causes $(n=100$ cases, $31.44 \%$ ) were the most common cause of sudden death. The predominant cardiac pathology was infarction accounting for $32.07 \%$ of all causes of sudden death, and pulmonary embolism with $19.49 \%$ was the leading cause at the pulmonary level.

\section{Introduction}

Sudden death is a natural death that occurs unexpectedly in an apparently healthy person within less than an hour of the onset of possible symptoms, after a brief agony [1]. This mode of occurrence is dramatic: with nearly 40.000 new cases /year of sudden death in France and around 300.000 cases /year in the United States, it constitutes a real public health problem whose solution will essentially be the prevention of Cardiovascular diseases [2,3]. In adults, cardiovascular, pulmonary and cerebral causes are predominant [1]. Although sudden death in adults is not exceptional in Africa, publications on this subject are rare [1]. The objectives of this work are to determine the socio-demographic characteristics of sudden deaths, and to identify causes in Togolese adults over 18 years of age.

\section{Methodology}

This is a retrospective study of cases of sudden death in Togolese adults over the age of 18 who were autopsied in the pathology anatomy department at the Sylvanus Olympio University Hospital Center in Lomé (Togo). All cases of autopsies performed from January 2009 to December 2018 (10 years) were included in the study. The documents studied were the requisitions issued by police authorities or the gendarmerie, the autopsy register, the autopsy reports. The parameters studied were the sociodemographic characteristics of sudden-death deaths, risk factors, the causes of sudden death in adults at autopsy, with a view to improving prevention.

The data was recorded on the Epidata 3.1 software. The data analysis was done on the software $\mathrm{R}$ in version 3.4.3. For the descriptive analysis, the quantitative variables were presented as mean and standard deviation and the qualitative variables as numbers and percentages.

\section{Results}


In total, there are 318 cases of sudden death recorded an average of 31.8 cases per year. There were 202 men and 116 women, a sex ratio of 1.8. The average age was $43 \pm 0.36$ years, the extreme 18 years and 75 years. Sudden deaths $(18.89 \%)$ were the second most common cause of autopsy after traffic accidents (74.2\%) (Table1). The place of death is at home $(n=244$ cases, $76.7 \%)$ and in hospitals $(n=74$ cases, $23.3 \%)$. Regarding risk factors, we noted obesity in 189 cases (59.4\%). with an umbilical adipose panicle varying between 7 and $12 \mathrm{~cm}$ thick.

The causes of death were dominated by cardiovascular causes excluding cerebral involvement $(\mathrm{n}=$ 173 cases, $54.40 \%)$ followed by pulmonary causes $(n=100$ cases, $31.44 \%)$ (Table2). The most common cardiac pathology was myocardial infarction. Myocardial infarction $(n=102$ cases, $58.96 \%)$ and accounted for $32.07 \%$ of all causes of sudden death. Coronary thrombosis ranked second with 33 cases (19.08\%) (Table3). There has been an increase in sudden cardiac deaths on a regular basis over the entire study period, from 7 cases in 2010, to 17 cases in 2018. This increase is mainly due to myocardial infarction, which represented 3 cases. in 2009 and 12 cases in 2018. We found in our series four bronchopulmonary causes of sudden death: pulmonary embolism $(n=62$ cases), acute pulmonary edema $(n=$ 16 cases), bronchopneumopathies ( $n=15$ cases) and tuberculosis $(n=7$ cases). Pulmonary embolism accounted for $19.49 \%$ of all causes of sudden death. Gynecological causes represented by erupted ectopic pregnancies in 10 cases, 4 cases of endometrial adenocarcinoma and one case of ovarian angiosarcoma. The digestive causes were hemoperitoines $(n=11$ cases $)$ and peritonitis $(n=2$ cas). Haemoperitoines were secondary in 6 cases with complicated cirrhosis hepatocarcinoma, in 2 cases with adenocarcinoma of the pancreas, in 2 cases with adenocarcinoma with renal cells and one case with small cell carcinoma of the pancreas.

The cerebral causes are intracranial hemorrhages in 10 cases and brain tumors in one case. The cerebromeningeal haemorrhages were composed of 8 cases under chronic dural hematoma, a broken aneurysm. Malaria is diagnosed in 6 cases of sudden death cases in patients who were immunocompromised for HIV.

\section{Discussion}

Sudden adult death is a major problem in both developing and developed countries. We identified 318 cases in 10 years, an annual frequency of 31.8 cases. Mohamed et al [4] had noted 476 cases in 3 years, an average of 158.7 cases /year. Ossei et al [5] found 1,470 cases over 9 years, an average of 163.33 cases /year. The frequencies of the African series are much lower than those of the developed countries. Indeed it is 300000 cases /year in the United States according to Zheng et al [3]. These low frequencies of the African series could be explained by still negligible demands of autopsies in the event of sudden death, linked to the sacred cultural character of death in our countries and the lack of systematic realization of scientific autopsies in hospitals. We noted a male predominance with 202 cases, a sex ratio $(\mathrm{H} / \mathrm{F})$ of 1.8. This observation is consistent with the majority of series where there was a male predominance. Mohamed et al [4] noted a sex ratio (H/F) of 2.97; Ossei et al [5] found a sex ratio (H/F) of 3.1. This male predominance is explained by the higher and earlier incidence of ischemic heart disease in 
men, a different susceptibility to ischemia, a different distribution of structural heart disease and the protective nature of estrogens [6,7]. The average age of our patients was $43 \pm 0.36$ years with extremes of 9 years and 75 years. Mohamed et al [4] noted an average age of 45.5 years. In developed countries, sudden death occurs mainly in the elderly with an average age of $68+20$ years $[2,8]$. This relatively low average age of African series can be explained by the much lower life expectancy in these developing countries.

Regarding risk factors, we noted obesity in 189 cases (59.4\%). with an umbilical adipose panicle varying between 7 and $12 \mathrm{~cm}$ thick. The specific association between abdominal obesity and sudden death has been described. In the Paris prospective study, there was a specific risk gradient between the abdominal diameter level and sudden death, while there was no association with death from myocardial infarction [9].

The causes of death were dominated by cardiovascular causes excluding cerebral involvement $(\mathrm{n}=$ 173 cases, $54.40 \%$ ) followed by pulmonary causes $(n=100$ cases, $31.44 \%)$. Cardiovascular causes are the leading cause of sudden death in all series. Mohamed et al [4] noted a predominance of cardiovascular causes with $48.7 \%$ of the causes of sudden death, followed by bronchopulmonary causes with $36 \%$ of the causes of sudden death. In Western countries, the incidence of sudden cardiac death is $88 \%$ of sudden deaths in middle-aged and elderly adults. In these developed countries in general the mortality was related to the complications of atherosclerosis. The prevention of nutritional and metabolic risk factors has reduced this mortality [10]. The most common cardiac pathology was myocardial infarction ( $n=102$ cases, $58.96 \%$ ) and accounted for $32.07 \%$ of all causes of sudden death, followed by coronary thrombosis, concordant with most reported series in the literature [11, 12]. There has been an increase in sudden cardiac deaths on a regular basis over the entire duration of the study, from 7 cases in 2010 , to 17 cases in 2018. This increase is mainly in myocardial infarction, which represented 3 cases in 2010 and 12 cases in 2018, concordant with certain African series $[4,13]$. This situation in the developing countries is explained by the urbanization anarchic with emergence of bad habits hygieno-dietary. We eat too much fat, too much sugar, too much salt and we do little physical activity, hence the appearance of cardiovascular risks factors.

\section{Limitations}

All cases of sudden death do not systematically, the subject of an autopsy. In addition, there is an absence of clear legislation of practice of the autopsies in our country.

\section{Declarations}

\section{Ethics approval and consent to participate}

This study received approval from the head of the laboratory department to be conducted. During counting and collecting data, the names of the deceased were not collected to preserve confidentiality. 
This study was approved by the head of the laboratory department of Sylvanus Olympio teaching Hospital (Ref $N^{\circ} 22 / 2019 /$ LAP/CHUSO).

\section{Consent for publication}

The Laboratory of Pathological Anatomy of Sylvanus Olympio Teaching Hospital, University of Lomé authorized the publication of this manuscript. All authors have read and approved the final manuscript to be submitted for publication.

\section{Availability of data and materials}

Extracted data are with the authors and available for sharing on request.

\section{Competing interest}

The authors declare that they have no competing interests.

\section{Funding}

None

\section{Acknowledgements}

Not applicable

\section{Authors' contribution}

$T D$ is responsible for the design of the study, undertook the field study, performed data collection, analysis, and interpretation, and wrote the manuscript. TDj participated in the design of the study, supervised the data collection, and participated in the data analysis. GNK is responsible for the overall scientific management of the study, the analysis and interpretation, and preparation of the final manuscript.

\section{References}

1. Charlier P, Brun L, Lorin de la Grandmaison G. An unusual sudden death. Ann Pathol. 2012;32(1):724.

2. Naneix AL, Périer MC, Beganton F, Jouven X, Lorin de la Grandmaison G. Sudden adult death: an autopsy series of 534 cases with gender and control comparison. J Forensic Leg Med. 2015;32:10- 
5.

3. Zheng ZJ, Croft JB, Giles WH, Mensah GA. Sudden cardiac death in the United States, 1989 to 1998. Circulation. 2001;104:2158-63.

4. Mohamed M, Drissa k, Mor N, Mamadou L. La mort subite de l'adulte, particularité en Afrique, à propos de 476 cas. Pan African Medical journal. 2013; 16 : 125-30.

5. Ossei PPS, Ayibor WG, Agagli BM, Aninkora OK, Fuseini G, Oduro-Manu et al. Profile of unnatural mortalities in Northern part of Ghana; a forensic-based autopsy study. J Forensic Leg Med. 2019;65:137-42.

6. Bougouin W, Lamhaut L, Marijon E, Jost D, Dumas F, Deye N, et al. SDEC Co-Investigators. Characteristics and prognosis of sudden cardiac death in Greater Paris: population-based approach from the Paris Sudden Death Expertise Center (Paris-SDEC). ntensive Care Med. 2014;40(6):846-54.

7. Kappert K, Böhm M, Schmieder R, Schumacher H, Teo K, Yusuf S, et al. ONTARGET/TRANSCEND investigators. Impact of sex on cardiovascular outcome in patients at high cardiovascular risk: analysis of the Telmisartan Randomized Assessment Study in ACE-Intolerant Subjects With Cardiovascular Disease (TRANSCEND) and the Ongoing Telmisartan Alone and in Combination With Ramipril Global End Point Trial (ONTARGET). Circulation. 2012;126(8):934-41

8. Ferrières J, Cambou JP. Epidemiology of acute coronary syndrome in France. Ann Cardiol Angeiol (Paris). 2007;56 Suppl 1:S8-15.

9. Empana JP, Ducimetiere P, Charles MA, Jouven X. Sagittal abdominal diameter and risk of sudden death in asymptomatic middleaged men: the Paris Prospective Study I. Circulation. 2004;110(18):2781-5.

10. Kornitzer M. [20 years of cardiovascular epidemiology. The epidemiologist's viewpoint. Rev Epidemiol Sante Publique. 1996;44(6):563-76.

11. Martens E, Sinner MF, Siebermair J, Raufhake C, Beckmann BM, Veith S,et al. Incidence of sudden cardiac death in Germany: results from an emergency medical service registry in Lower Saxony. Europace. 2014;16(12):1752-8.

12. Talle MA, Bonny A, Scholtz W, Nel G, Chin A, Karaye KM, et al. Status of cardiac arrhythmia services in Africa in 2018: a PASCAR Sudden Cardiac Death Task Force report Cardiovasc J Afr. 2018; 29(2): 115-121.

13. Ossei PPS, Ayibor WG, Agagli BM, Aninkora OK, Fuseini G, Oduro-Manu G, Ka-Chungu S. Profile of unnatural mortalities in Northern part of Ghana; a forensic-based autopsy study. J Forensic Leg Med. 2019;65:137-142.

\section{Tables}

\section{Table 1: Place of Sudden Death in Autopsy Patterns}




\begin{tabular}{lcc}
\hline & Number of cases (n) & \% \\
\hline Public road accident & 1249 & 74.21 \\
Sudden adult death & 318 & 18.89 \\
Blows and wounds & 46 & 2.73 \\
Drowning & 23 & 1.37 \\
Works accidents & 22 & 1.31 \\
Suicide & 19 & 1.13 \\
Hanging & 6 & 0.36 \\
Total & $\mathbf{1 6 8 3}$ & 100 \\
\hline
\end{tabular}

Table 2: Distribution of Sudden Deaths by Cause

\begin{tabular}{lcc}
\hline & Number of cases (n) & \% \\
\hline Heart pathology & 173 & 54.40 \\
Bronchopulmonary pathology & 100 & 31.44 \\
Gynecological pathologies & 15 & 4.72 \\
Digestive pathologies & 13 & 4.09 \\
Brain pathology & 11 & 3.46 \\
Malaria & 6 & 1.89 \\
Total & $\mathbf{3 1 8}$ & $\mathbf{1 0 0}$ \\
\hline
\end{tabular}

Table 3: Distribution by Type of Cardiac Pathology 


\begin{tabular}{lcc}
\hline & Number of cases (n) & $\%$ \\
\hline Infarct & 102 & 58.96 \\
Thrombosis & 33 & 19.08 \\
\hline Cardiomyopathy & 23 & 13.29 \\
\hline Aneurysm rupture & 11 & 6.36 \\
\hline Endocarditis & 03 & 1.73 \\
\hline Pricarditis & 01 & 0.58 \\
Total & 173 & $\mathbf{1 0 0}$ \\
\hline
\end{tabular}

